\title{
Desenvolvimento de um Software que Transfere Dados USB para uma Tabela MySQL - Etapa do Sistema de Automação da Rede de Tratamento de Esgoto da FT/Unicamp
}

\author{
Leonardo Carlos Bravo Castañeda (IC), Talía Simões dos Santos (PQ).
}

\section{Resumo}

In this project it was developed an alternative to measure the level of sewage at School of Technology. A sensor has been previously installed in the sewer treatment and we present the processing of the data collected by the sensor. A code was written for an Arduino UNO board in order to get the sewage level at each second. The board was connected to a computer through an USB serial port and the data was stored in a database. The aim of this project was to automate the sewage measurement.The manipulation of data was done by a program written in Java and the Database Management System used was MySQL.

Keywords: Java Language, Database, SQL, Arduino UNO, MySQL.

\section{Introdução}

Dentro da Faculdade de Tecnologia (FT) da Unicamp existe uma estação compacta de tratamento de esgoto, cuja leitura do nível de efluente é feita manualmente com uma régua para coleta dos valores. Além de não ser totalmente confiável devido à sujeira, uma vez que a régua fica o tempo todo dentro do tubo e já não está mais limpa, algum pequeno desvio no nível pode ser imperceptível ao olho humano.

Então, para aperfeiçoar esta leitura, a ideia do projeto é fazer este trabalho ser automático, ou seja, sem precisar que o técnico faça a leitura e sem necessitar de hidrômetro digital.

\section{Resultados e Discussão}

Os dados lidos pela placa Arduino mostraram o nível do esgoto. Estes dados são enviados através da porta serial e foram analisados para posteriormente serem armazenados num banco de dados. Estas conexões envolvem as linguagens Java, C (Arduino) e SQL. Os dados são armazenados a cada segundo, criando uma melhor amostra para o especialista [1-3]. A Figura 1 mostra o protótipo desenvolvido.

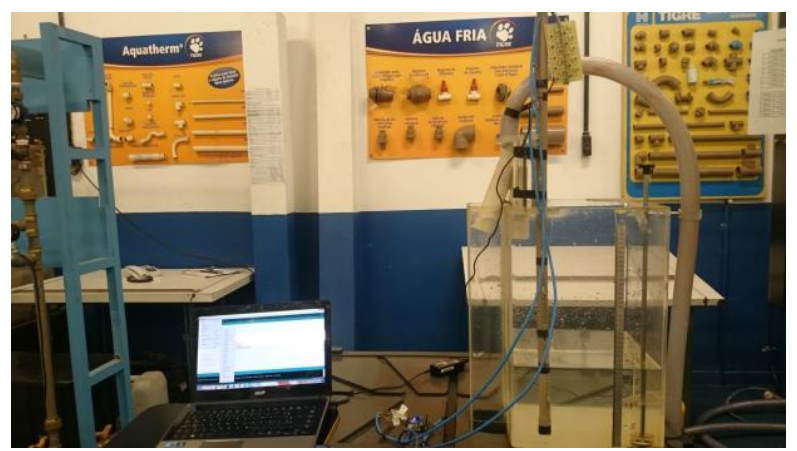

Figura 1. Protótipo criado.
A Fig. 2 mostra a rede de tratamento de esgoto.

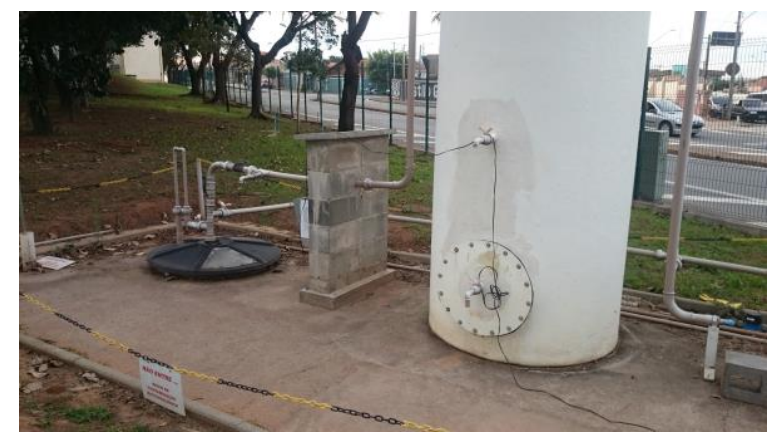

Figura 2. Rede de Esgoto - FT/UNICAMP.

\section{Conclusões}

Com o projeto, foi possível observar como a automação facilitou a medição do nivel do esgoto. Com o novo método de medição é possivel saber com precisão o exato nível do esgoto. Foi demonstrado como linguagens de programação úteis como Arduino, Java, SQL ajudam em aplicações do dia a dia.

\section{Agradecimentos}

Gostaria de agradecer a professora Talía Simões dos Santos e Rodrigo Luiz Ximenez, da equipe técnica do Laboratório de Telecomunicações. Aos meus amigos, Kaique Algarte e Amanda Gonçalves. Também agradeço aos meus pais Leonardo Bravo e Zady Castañeda. Ao CNPq pelo apoio financeiro.

1DEITEL, Paul; DEITEL, Harvey. Java - Como Programar. $8^{\text {a }}$ edição. Pearson - Prentice Hall, 2010. 1176 p.

${ }^{2}$ MANZANO, José Augusto N. G. Microsoft SQL Server 2012 Express: Guia Prático e Interativo. Editora Érica, 2012. 208 p.

3Arduino. Disponível em: <http://forum.arduino.cc/> Acesso em: $14 / 07 / 2015$. 